OPEN ACCESS

Edited by:

Kevin Lu,

University of South Carolina,

United States

Reviewed by:

Jing Yuan,

Fudan University, China

Xiaomeng Yue,

University of Cincinnati, United States

*Correspondence:

Hongchao Li

lihongchao@cpu.edu.cn

†These authors have contributed equally to this work and share first authorship

Specialty section:

This article was submitted to

Health Economics,

a section of the journal

Frontiers in Public Health

Received: 31 December 2020 Accepted: 28 January 2021

Published: 19 February 2021

Citation:

Chen $P$, Zhang $M$, Zhang $Y$, Su X Chen J, Xu B, Tao J, Wang Z, Ma A and $\mathrm{LiH}$ (2021) Economic Burden of Myocardial Infarction Combined With

Dyslipidemia.

Front. Public Health 9:648172. doi: 10.3389/fpubh.2021.648172

\section{Economic Burden of Myocardial Infarction Combined With Dyslipidemia}

\author{
Pingyu Chen ${ }^{1,2 t}$, Mengran Zhang ${ }^{1 t}$, Yan Zhang ${ }^{3}, X_{i} \mathrm{Su}^{4}$, Jiyan Chen ${ }^{5}$, Biao Xu ${ }^{6}$, \\ Jianhong Tao ${ }^{7}$, Zhen Wang ${ }^{8}$, Aixia Ma ${ }^{1,2}$ and Hongchao $\mathrm{Li}^{1,2 *}$ \\ ${ }^{1}$ Department of Health Economics, China Pharmaceutical University, Naniing, China, ${ }^{2}$ Center for Pharmacoeconomics and \\ Outcomes Research, China Pharmaceutical University, Nanjing, China, ${ }^{3}$ Department of Cardiology, Peking University First \\ Hospital, Beijing, China, ${ }^{4}$ Department of Cardiology, Wuhan Asia Heart Hospital, Wuhan, China, ${ }^{5}$ Department of Cardiology, \\ Guangdong Provincial People's Hospital, Guangzhou, China, ${ }^{6}$ Department of Cardiology, Nanjing Gulou Hospital, Nanjing, \\ China, ${ }^{7}$ Department of Cardiology, Sichuan Provincial People's Hospital, Chengdu, China, ${ }^{8}$ Department of Cardiology, \\ Zhongshan Hospital, Fudan University, Shanghai, China
}

Background: Dyslipidemia is a common comorbidity and an important risk factor for myocardial infarction (MI). This study aimed to examine the economic burden of $\mathrm{Ml}$ combined with dyslipidemia in China.

Methods: Patients who were hospitalized due to Ml combined with dyslipidemia in 2016 were enrolled. Costs were measured based on electronic medical records and questionnaires. The annual costs were analyzed by conducting descriptive statistics, univariable, and multivariable analyses.

Results: Data of 900 patients were analyzed, and 144 patients were dead during the follow-up. The majority of patients were aged $51-70$ years $(n=563,62.55 \%)$ and males $(n=706,78.44 \%)$. For all-cause costs, the median annual direct medical costs, direct non-medical costs, indirect costs, and total costs were RMB 13,168 (5,212-29,369), RMB 600 (0-1,750), RMB 676 (0-1,787), RMB 15,361 (6,440-33,943), respectively; while for cardiovascular-related costs, the corresponding costs were RMB 12,233 (3,795-23,746), RMB 515 (0-1,680), RMB 587 (0-1,655), and RMB 14,223 $(4,914-28,975)$, respectively. Lifestyle and complications significantly affected both all-cause costs and cardiovascular-related costs.

Conclusions: Increasing attention should be paid to encourage healthy lifestyle, and evidence-based medicine should focus on optimal precautions and treatments for complications, to reduce the economic burden among Ml patients with a comorbid dyslipidemia.

Keywords: economic burden, myocardial infarction, dyslipidemia, older adults, China 


\section{INTRODUCTION}

There are $\sim 290$ million cardiovascular patients in China, including 11 million patients with coronary atherosclerotic heart disease, in which myocardial infarction (MI) is the most acute and dangerous disease (1). Cardiovascular diseases have long been the leading cause of death among Chinese residents, while the mortality rate of MI in China had been on the rise from 2002 to 2016, particularly since 2005 . In 2016, MI's mortality rate in urban and rural areas reached 58.69 per 100,000 and 74.72 per 100,000 individuals in China, respectively (2).

Dyslipidemia is one of the most significant risk factors for MI. Patients with a history of MI are at high risk and should strictly control their low-density lipoprotein-cholesterol levels (LDL-C) $(3,4)$. According to the 2002 China Health and Nutrition Survey (CHNS) (5), the 2010 China Chronic Kidney Disease Working Group Survey (6), the 2011 CHNS (7), and the 2015 Report on Nutrition and Chronic Diseases of Chinese residents (8), the prevalence of Dyslipidemia in Chinese people aged $\geq 18$ years in 2002, 2010, 2011, and 2012 were $18.60,33.97,39.91$, and $40.40 \%$, respectively. In the past 10 years, the prevalence of dyslipidemia as well as MI in Chinese adults have risen sharply. It is estimated that elevated serum cholesterol levels will cause 9.2 million patients with cardiovascular disease (CVD) from 2010 to 2030 (9).

MI, in turn, carries a heavy economic burden. In 2014, the annual direct medical costs of cardiovascular and cerebrovascular diseases in China exceeded 130 billion yuan, accounting for over $22 \%$ of the total medical costs in the same year (10). At present, there are few studies directly investigating the economic burden of MI in China. The government bulletin showed that the total and average per hospitalization costs of MI in 2016 were RMB 19.085 billion and RMB 26056.9, respectively, with annual average growth rates of 29.15 and $7.12 \%$ (1). The costs of MI hospitalizations increased by $56.8 \%$ from 2007 to 2012 in Beijing after adjusting inflation (11). Models predict that universal treatments for hypertension and dyslipidemia patients could avert 10-20 million MIs and between 3 and 10 million CVD deaths during 2016-2030, producing a positive social value net of healthcare costs high as USD 932 billion (12).

Studies on the burden of disease in China only focus on patients' hospitalization costs. There has been no relevant study on this extremely high-risk population of MI with dyslipidemia. Therefore, this study combined patients' medical records and questionnaires to investigate the economic burden for patients with MI and dyslipidemia in China's realworld environment. Our research filled the literature gap by providing the most recent data on the economic burden of MI combined with dyslipidemia from the social perspective, and the factors that potentially impact economic burden were analyzed. Therefore, our results may highlight the importance of providing prevention measures and management intervention. The up-to-date data may be used as important cost parameters for economic evaluations, such as cost of illness or costeffectiveness/utility analysis.

\section{MATERIALS AND METHODS}

\section{Study Design}

This is a multicenter study combining retrospective cohort and cross-sectional research and was conducted from a social perspective. Six tertiary hospitals from major cities-Beijing, Shanghai, Wuhan, Nanjing, Guangzhou, and Chengdu, China were chosen as research centers for data collection.

Data were collected according to medical record review and questionnaires, including demographic characteristics (gender, age, marital status, type of medical insurance, income, etc.), lifestyle (smoking, drinking, diet, exercise, etc.), disease characteristics (complications and the cause of death, etc.), hospitalization costs and costs of outpatient (medical and pharmaceutical expenses, nursing expenses, loss of time and labor of the patients and their families, etc.). As the simplified questionnaires were used for the deceased, information, such as lifestyle, income, accommodation and transportation expenses, and out-of-hospital visits were not collected and not able to be analyzed accordingly. The medical record review and questionnaires were linked by patients' name as well as the unique ID number or medical card number.

For all patients, their first hospitalization from January 1, 2016 to December 31, 2016 was considered as the index event, and their related 1-year post-index data was collected and analyzed. Key information of the data is shown in Table 1, the time frame of all the data was 1-year post-index hospitalization, indicating that the cost of index hospitalization was not included in our study

The study was approved by the Ethics Committees of all the six participating hospitals. Written informed consent was provided by all participants before the data collection and conduction of the research. Before analysis, the patient data were anonymized and de-identified.

\section{Study Population}

Inclusion criteria in this study included: patients hospitalized with myocardial infarction (MI) from January 1, 2016 to December 31, 2016. The earliest hospitalization was considered as the index hospitalization; patients for whom in the first blood lipid examination of the index hospitalization, the LDLC was $\geq 1.8 \mathrm{mmol} / \mathrm{L}$ or were using lipid-regulating drugs. Exclusion criteria included: patients who died during the index hospitalization; patients who participated in clinical trials after the index hospitalization; patients or family members (if the patient had died) who were not willing to participate in survey or could not correctly understand and answer relevant questions due to communication barriers.

\section{Outcomes}

This study's primary outcomes were the annual total costs of survivors and deceased, which were reported in all-cause and CV-related costs, as well as the direct medical, direct non-medical, and indirect costs. Here CV-related indicates cardiovascular diseases, including MI, hypertension, postpercutaneous transluminal coronary intervention (PCI), peripheral arterial disease, etc. The secondary outcomes were the 
TABLE 1 | Key information about the data.

\begin{tabular}{|c|c|c|}
\hline Variable & Patients & Source \\
\hline \multicolumn{3}{|l|}{ Patient characteristics } \\
\hline Survival situation & S, D & QS \\
\hline Cause of death & D & QS \\
\hline Gender & S, D & EMR \\
\hline Birthday & S, D & EMR \\
\hline Height (cm) & $S, D$ & EMR \\
\hline Weight (kg) & $S, D$ & EMR \\
\hline Medical insurance & S, D & EMR \\
\hline Medical history & S, D & EMR \\
\hline Education status & S & QS \\
\hline Marital status & S & QS \\
\hline Employment status & S & QS \\
\hline Income level (RMB) & S & QS \\
\hline Smoking & S & QS \\
\hline Drinking & S & QS \\
\hline Diet (whole grains) & S & QS \\
\hline Diet (High-fat and high-cholesterol) & S & QS \\
\hline Sports & S & QS \\
\hline \multicolumn{3}{|l|}{ Costs (hospitalization and outpatient) } \\
\hline Direct medical and pharmaceutical expenses & S, D & EMR \\
\hline Accommodation and transportation expenses & S & QS \\
\hline Nursing expenses & S & QS \\
\hline Loss of time and labor of the patients & S & QS \\
\hline Loss of time and labor of their companions & S & QS \\
\hline The income of companions & $S$ & QS \\
\hline Out-of-hospital visit times and costs* & S & QS \\
\hline Health care products costs & S & QS \\
\hline
\end{tabular}

S, survivors; D, deceased; QS, questionnaire survey; EMR, electronic medical records. ${ }^{*}$ Costs incurred in other hospitals and pharmacies.

\section{Statistical Analysis}

Described for the baseline characteristics and costs by survival status. Categorical variables were reported as numbers and proportions, and continuous variables were reported as medians and interquartile ranges.

Univariable and multivariable analyses were applied to the study of the economic burden's influencing factors. In the univariable analysis, the chi-square test was performed for categorical variables; the Wilcoxon rank-sum test or the KruskalWallis test was used for continuous variables.

Multivariable analysis was performed in generalized linear model (GLM) with gamma distribution and log link function. Multivariable analysis was not performed for the deceased's total annual costs due to the lack of certain baseline information. Patients' baseline information (age, gender, etc.), lifestyle (smoking, drinking, etc.), and disease history (whether firstepisode MI, etc.) were included as independent variables in GLM. The annual all-cause and CV-related total costs of survivors were used as dependent variables.

We combined some variables' classifications in the multivariable analysis since some variables had too many original categories. (a) Medical insurance types: BMISUE, BMISUR, and NRCMS were combined into one category (basic medical insurance). (b) Education status: not graduated from primary school, primary school were combined into primary education; Junior high school, high school, technical secondary school/junior college graduate were combined into medium education; Bachelor, master and doctor were combined into high education. (c) Marital status: unmarried, divorce, and death of a spouse were combined into current single. (d) Employment status: formal employees, individuals, and freelancers were combined into formal wage; Farming, unemployed were combined into non-formal wage.

The significance level was set at $P<0.05$ with a two-tailed test. Data were analyzed using Stata SE 15 (Stata Software, StataCorp) and SPSS 22.0 (SPSS Software, IBM Corp.).

\section{RESULTS}

influencing factors for the annual total all-cause and CV-related costs of survivors.

Direct medical costs included registration, diagnosis, examination, medicine (including pharmacy purchase), operation, bed fee, material, nursing, and other expenses. The direct medical costs were obtained through electronic medical records. Out-of-hospital direct medical costs of the survivors were obtained through questionnaires, while the deceased's out-of-hospital direct medical costs were not collected.

Direct non-medical costs included expenses related to patient caregivers, accommodation and transportation, and health care products, etc. The survivors' data were collected through questionnaires, while the data of the deceased were not collected.

Indirect costs were calculated by the human capital method (13) to calculate the time and labor loss of the patients and their accompanying family members. The monthly income (sum of the pension and additional monthly income for retirees, sum of the monthly salary and extra monthly income for others) of the survivors was derived from the questionnaires. Such data were also not collected for the deceased.

\section{Patient Characteristics}

The baseline information of patients is shown in Tables 2, 3. A total of 900 patients were included in this study, including $756(84.00 \%)$ survivors and $144(16.00 \%)$ deceased. Among the deceased, 109 (75.69\%) patients died due to CV-related diseases.

There were more males $(n=706,78.44 \%)$ than females $(n=$ $194,21.56 \%)$. The average age of all patients was 62.07 years (SD: $11.45)$, and patients aged 60-70 years were the majority $(n=307$, $34.11 \%)$. In terms of body mass index (BMI), most patients $(n=$ $450,50.00 \%)$ were overweight $(23.9<\mathrm{BMI} \leq 27.9)$ or obese $(\mathrm{BMI}$ $>27.9)(n=134,14.89 \%)$. Regarding the medical history, $94.67 \%$ $(n=852)$ patients were of first-episode MI, 64.67\% $(n=582)$ had undergone PCI, and most complications were hypertension ( $n=537,59.67 \%)$, type 2 diabetes $(n=276,30.67 \%)$, and lipid metabolism disorder $(n=269,29.89 \%)$. For the type of medical insurance, $88.33 \%$ ( $n=795)$ had one of the following basic medical insurance which covered majority people in China: basic medical insurance system for urban employees (BMISUE), basic 
TABLE 2 | Baseline information of all patients $(N=900)$.

\begin{tabular}{|c|c|c|}
\hline Variable & Number of cases & $\%$ \\
\hline \multicolumn{3}{|l|}{ Survival situation } \\
\hline Survival & 756 & 84.00 \\
\hline Death & 144 & 16.00 \\
\hline \multicolumn{3}{|l|}{ Cause of death $(N=144)$} \\
\hline Non-cardiovascular causes & 35 & 24.31 \\
\hline Cardiovascular causes & 109 & 75.69 \\
\hline \multicolumn{3}{|l|}{ Gender } \\
\hline Female & 194 & 21.56 \\
\hline Male & 706 & 78.44 \\
\hline Age $^{\star}$ & 62.07 (SD:11.45) & \\
\hline \multicolumn{3}{|l|}{ Age classification (year) } \\
\hline $18-50$ & 127 & 14.11 \\
\hline $51-60$ & 256 & 28.44 \\
\hline $61-70$ & 307 & 34.11 \\
\hline $70-$ & 210 & 23.33 \\
\hline Height $(\mathrm{cm})^{\star}$ & 166.57 (SD:7.04) & \\
\hline Weight $(\mathrm{kg})^{\star}$ & 69.39 (SD:11.77) & \\
\hline \multicolumn{3}{|l|}{ BMI $\left(\mathrm{kg} / \mathrm{m}^{2}\right)$} \\
\hline-18.4 & 22 & 2.44 \\
\hline $18.5-23.9$ & 294 & 32.67 \\
\hline $24.0-27.9$ & 450 & 50.00 \\
\hline $28.0-$ & 134 & 14.89 \\
\hline \multicolumn{3}{|l|}{ Medical insurance } \\
\hline Basic medical insurance system for urban employees & 584 & 64.89 \\
\hline Basic medical insurance for urban residents & 122 & 13.56 \\
\hline The new rural cooperative medical care system & 89 & 9.89 \\
\hline Full public expense coverage & 42 & 4.67 \\
\hline Uninsured & 53 & 5.89 \\
\hline Other & 8 & 0.89 \\
\hline \multicolumn{3}{|l|}{ Medical history } \\
\hline Myocardial infarction (MI) & 48 & 5.33 \\
\hline Hypertension & 537 & 59.67 \\
\hline Type 2 diabetes & 276 & 30.67 \\
\hline Disorder of lipid metabolism & 269 & 29.89 \\
\hline Post-PCl & 582 & 64.67 \\
\hline Peripheral artery disease & 118 & 13.11 \\
\hline
\end{tabular}

PCl, percutaneous coronary intervention; BMI, Body mass index.

*Mean and standard deviation were reported.

\#Patients who experienced MI before index hospitalization.

medical insurance system for urban residents (BMISUR), and the new rural cooperative medical system (NRCMS).

Among the 756 surviving patients, the majority ( $n=560$, $74.07 \%)$ were of moderate degree (middle-school or equivalent), most ( $n=712,94.18 \%)$ were married, up to $66.53 \%(n=503)$ were retirees, $49.86 \%$ had income more than RMB 2,400 and less than RMB 5,500. In terms of lifestyle, the majority had no history of smoking ( $n=496,65.61 \%)$ or drinking ( $n=515,68.12 \%)$, often ate high-fiber foods and grains $(n=534,70.63 \%)$ and controlled high-fat and high-cholesterol food intake $(n=550$, 72.75\%); 61.77\% ( $n=467)$ often exercised.
TABLE 3 | Baseline personal and lifestyle information for surviving patients $(N=756)$.

\begin{tabular}{|c|c|c|}
\hline Variable & Number of cases & $\%$ \\
\hline \multicolumn{3}{|l|}{ Education status } \\
\hline Not graduated from primary school & 51 & 6.75 \\
\hline Primary school & 53 & 7.01 \\
\hline Junior high school & 220 & 29.10 \\
\hline High school & 176 & 23.28 \\
\hline Technical secondary school/junior college graduate & 164 & 21.69 \\
\hline Bachelor & 80 & 10.58 \\
\hline Master and doctor & 11 & 1.46 \\
\hline \multicolumn{3}{|l|}{ Marital status } \\
\hline Unmarried & 7 & 0.93 \\
\hline Married & 712 & 94.18 \\
\hline Divorce & 12 & 1.59 \\
\hline Death of a spouse & 25 & 3.31 \\
\hline \multicolumn{3}{|l|}{ Employment status } \\
\hline Formal employees & 104 & 13.76 \\
\hline Individuals and freelancers & 40 & 5.29 \\
\hline Retired & 503 & 66.53 \\
\hline Farming & 31 & 4.10 \\
\hline Unemployed & 60 & 7.94 \\
\hline Other & 18 & 2.38 \\
\hline \multicolumn{3}{|l|}{ Income level (RMB)* } \\
\hline $0-2,400$ & 187 & 24.74 \\
\hline $2,401-4,000$ & 186 & 24.60 \\
\hline $4,001-5,500$ & 191 & 25.26 \\
\hline $5,501-$ & 192 & 25.40 \\
\hline \multicolumn{3}{|l|}{ Smoking } \\
\hline No smoking history/Give up smoking & 496 & 65.61 \\
\hline Sometimes & 88 & 11.64 \\
\hline Often & 172 & 22.75 \\
\hline \multicolumn{3}{|l|}{ Drinking } \\
\hline No drinking history/Give up drinking & 515 & 68.12 \\
\hline Sometimes & 186 & 24.60 \\
\hline Often & 55 & 7.28 \\
\hline \multicolumn{3}{|l|}{ Diet (whole grains) } \\
\hline Often & 534 & 70.63 \\
\hline Sometimes & 214 & 28.31 \\
\hline Never & 8 & 1.06 \\
\hline \multicolumn{3}{|l|}{ Diet (high-fat and high-cholesterol) } \\
\hline Often control & 550 & 72.75 \\
\hline Sometimes control & 170 & 22.49 \\
\hline Never control & 36 & 4.76 \\
\hline \multicolumn{3}{|l|}{ Sports } \\
\hline Often & 467 & 61.77 \\
\hline Sometimes & 178 & 23.54 \\
\hline Never & 111 & 14.68 \\
\hline
\end{tabular}

*Income is grouped according to quartile.

\section{Total Annual Economic Burden}

Table 4 reports the median annual economic burden of the patients. For the all-cause economic burden, the median annual 
TABLE 4 | Median annual economic burden.

\begin{tabular}{|c|c|c|c|}
\hline Variable & Survivors $(n=756)$ & Deceased $(n=144)$ & Total $(n=900)$ \\
\hline \multicolumn{4}{|l|}{ All-cause } \\
\hline \multicolumn{4}{|l|}{ Hospitalization } \\
\hline Direct medical costs & $0(0-9,885)$ & $0(0-12,990)$ & $0(0-10,000)$ \\
\hline Direct non-medical costs & $0(0-600)$ & NA & $0(0-600)$ \\
\hline Indirect costs & $0(0-213)$ & NA & $0(0-213)$ \\
\hline Direct medical costs & $10,095(4,143-15,141)$ & $1,142(0-6,443)$ & $9,006(2,717-14,565)$ \\
\hline Direct non-medical costs & $120(0-600)$ & NA & $120(0-600)$ \\
\hline Indirect costs & $423(0-1,120)$ & NA & $423(0-1,120)$ \\
\hline Total cost of outpatient and emergency & $12,146(5,080-17,997)$ & $1,142(0-6,443)$ & $10,185(3,300-17,141)$ \\
\hline \multicolumn{4}{|l|}{ Total } \\
\hline Total costs & $16,737(9,224-35,025)$ & $2,547(0-21,085)$ & $15,361(6,440-33,943)$ \\
\hline \multicolumn{4}{|l|}{ Cardiovascular-related } \\
\hline \multicolumn{4}{|l|}{ Hospitalization } \\
\hline Direct medical costs & $0(0-8,000)$ & $0(0-0)$ & $0(0-7,460)$ \\
\hline Direct non-medical costs & $0(0-500)$ & NA & $0(0-500)$ \\
\hline Indirect costs & $0(0-0)$ & NA & $0(0-0)$ \\
\hline Total cost of hospitalization & $0(0-10,764)$ & $0(0-0)$ & $0(0-10,063)$ \\
\hline \multicolumn{4}{|l|}{ Outpatient } \\
\hline Direct medical costs & $9,674(3,383-14,469)$ & $888(0-5,164)$ & $8,014(2,257-13,813)$ \\
\hline Direct non-medical costs & $90(0-600)$ & NA & $90(0-600)$ \\
\hline Indirect costs & $373(0-1,013)$ & NA & $373(0-1,013)$ \\
\hline
\end{tabular}

NA, Not applicable (Data for the deceased was not collected).

All the costs were reported as medians and interquartile ranges.

hospitalization costs, outpatient costs, and annual costs for all patients were RMB 0 (IQR: 0-12,756), RMB 10,185 (IQR: 3,30017,141), and RMB 15,361 (IQR: 6,440-33,943), respectively. The corresponding average annual costs were RMB 18,641 (SD: 45,429), RMB 14,698 (SD: 23602), and RMB 33,878 (SD: $54,029)$, respectively.

For the CV-related economic burden, the median annual hospitalization costs, outpatient costs, and annual costs for all patients RMB 0 (IQR: 0-10,063), RMB 9,341 (IQR: 2,74416,208), RMB 14,223 (IQR: 4,914-28,975). The corresponding average annual costs were RMB 15,480 (SD: 37,233), RMB 12,759 (SD: 19,044), and RMB 28,777 (SD: 43,390), respectively.

The median annual ratio of CV-related costs to allcause costs was high. The direct medical costs and the hospitalization costs accounted for the largest proportion of total costs.

\section{Univariable Analysis}

The univariable analysis results of the annual all-cause and CVrelated costs of survivors are shown in Supplementary Table 1. The corresponding results of the deceased are shown in Supplementary Table 2.

For the survivors, there were significant differences in the annual all-cause costs among patients with different age groups $(P=0.049)$, employment status $(P=0.023)$, income levels $(P=$ $0.036)$, smoking status $(P=0.016)$, drinking status $(P=0.016)$, and dietary control conditions $(P=0.020)$. Complications, such as hypertension $(P=0.005)$, type 2 diabetes $(P=0.000)$, and PCI $(P=0.033)$ significantly affected the annual all-cause total costs. Regarding CV-related costs, patients with different smoking status $(P=0.009)$ and complications including hypertension $(P=0.003)$ and type 2 diabetes $(P=0.014)$ had significantly different costs. 
TABLE 5 | Multivariate analysis results of all-cause economic burden on survivors.

\begin{tabular}{|c|c|c|c|c|}
\hline \multicolumn{2}{|c|}{ Variable } & \multirow{2}{*}{$\begin{array}{c}\text { Costs }^{\#} \\
18,693(9,425-43,559)\end{array}$} & \multirow{2}{*}{$\begin{array}{c}\text { Coef. } \\
0\end{array}$} & \multirow[t]{2}{*}{$P$-value } \\
\hline Gender & Male & & & \\
\hline & Female & $16,404(9,102-34,592)$ & -0.110 & 0.411 \\
\hline \multirow[t]{3}{*}{ Age classification (year) } & $18-50$ & $15041(6,599-23,610)$ & 0 & \\
\hline & $51-60$ & $16,710(8,577-3,149)$ & 0.092 & 0.552 \\
\hline & $61-70$ & $17,344(9,920-46,418)$ & 0.264 & 0.136 \\
\hline \multirow{3}{*}{ BMI $\left(\mathrm{kg} / \mathrm{m}^{2}\right)$} & $18.5-23.9$ & $16,177(9,123-43,283)$ & 0.250 & 0.400 \\
\hline & $24.0-27.9$ & $16,912(8,988-34,770)$ & 0.438 & 0.135 \\
\hline & $28.0-$ & $15,622(9,425-27,838)$ & 0.163 & 0.604 \\
\hline \multirow[t]{2}{*}{ Medical insurance } & Basic medical insurance & $16,712(9,287-34,837)$ & 0 & \\
\hline & Full public expense coverage & $25,998(13,336-59,013)$ & 0.107 & 0.643 \\
\hline \multirow{2}{*}{ Education status } & Medium education & $16,851(9,322-37,300)$ & 0.149 & 0.328 \\
\hline & High education & $17,541(6,909-37,874)$ & 0.200 & 0.355 \\
\hline \multirow[t]{2}{*}{ Marital status } & Current single & $21,626(10,719-55,221)$ & 0 & \\
\hline & Married & $16,603(9,067-34,542)$ & -0.361 & 0.070 \\
\hline \multirow[t]{4}{*}{ Employment status } & Formal wage & $15,641(7,243-26,712)$ & 0 & \\
\hline & Non-formal wage & $17,619(10,179-42,556)$ & 0.081 & 0.617 \\
\hline & Retired & $14,884(9,385-28,025)$ & 0.336 & 0.126 \\
\hline & Other & $10,405(5,557-16,530)$ & -0.243 & 0.433 \\
\hline \multirow[t]{3}{*}{ Income level (RMB) } & $0-2,400$ & $6,451(13,941-23,145)$ & 0 & \\
\hline & $2,401-4,000$ & $10,588(18,067-54,158)$ & 0.452 & $0.003^{\star *}$ \\
\hline & $4,001-5,500$ & $10,083(16,504-31,846)$ & 0.297 & 0.059 \\
\hline Type 2 diabetes & Yes & $20,355(11,110-55,567)$ & 0.259 & $0.012^{*}$ \\
\hline \multirow[t]{2}{*}{ Disorder of lipid metabolism } & No & $16,124(8,867-37,586)$ & 0 & \\
\hline & Yes & $17,711(9,524-30,688)$ & -0.056 & 0.585 \\
\hline \multirow[t]{2}{*}{ Post-PCl } & No & $16,910(9,042-64,246)$ & 0 & \\
\hline & Yes & $16,664(9,258-29,721)$ & -0.429 & $0.000^{\star *}$ \\
\hline \multirow[t]{2}{*}{ Peripheral artery disease } & No & $16,830(9,219-35,862)$ & 0 & \\
\hline & Yes & $15,587(9,008-31,984)$ & -0.104 & 0.447 \\
\hline \multirow[t]{3}{*}{ Smoking } & No smoking history/Give up smoking & $17,823(10,131-42,575)$ & 0 & \\
\hline & Sometimes & $14,768(6,002-21,348)$ & -0.465 & $0.002^{* *}$ \\
\hline & Often & $14,751(8,098-27,551)$ & -0.244 & $0.047^{*}$ \\
\hline \multirow[t]{3}{*}{ Drinking } & No drinking history/Give up drinking & $17,418(9,425-43,559)$ & 0 & \\
\hline & Sometimes & $16,734(8,331-28,395)$ & -0.206 & 0.065 \\
\hline & Often & $13,628(5,883-21,897)$ & -0.293 & 0.116 \\
\hline \multirow[t]{3}{*}{ Diet (whole grains) } & Often & $17,485(8,988-34,770)$ & 0 & \\
\hline & Sometimes & $15,304(9,553-36,038)$ & -0.032 & 0.771 \\
\hline & Never & $19,268(7,859-49,900)$ & -0.313 & 0.489 \\
\hline Diet (High-fat and high-cholesterol) & Often control & $17,823(9,954-37,874)$ & 0 & \\
\hline
\end{tabular}




\begin{tabular}{|c|c|c|c|c|}
\hline \multicolumn{2}{|c|}{ Variable } & \multirow{2}{*}{$\begin{array}{c}\text { Costs }^{\#} \\
14,223(7,286-25,787)\end{array}$} & \multirow{2}{*}{$\begin{array}{l}\text { Coef. } \\
-0.282\end{array}$} & \multirow{2}{*}{$\begin{array}{r}\boldsymbol{P} \text {-value } \\
0.016^{\star}\end{array}$} \\
\hline & Sometimes control & & & \\
\hline & Never control & $16,568(7,087-42,316)$ & -0.134 & 0.549 \\
\hline \multirow{2}{*}{ Sports } & Sometimes & $16,877(9,789-36,038)$ & 0.254 & $0.030^{*}$ \\
\hline & Never & $18,595(10,933-51,003)$ & 0.228 & 0.091 \\
\hline
\end{tabular}

$\mathrm{PCl}$, percutaneous coronary intervention; BMI, body mass index.

${ }^{*} p<0.05,{ }^{* *} p<0.01$.

\#All the costs were reported as medians and interquartile ranges.

For the deceased, there were significant differences in the annual all-cause costs among patients with different causes of death $(P=0.021)$, BMI $(P=0.049)$, and medical insurance type $(P=0.041)$. In addition, substantial differences existed in the annual CV-related costs among patients with different BMIs $(P$ $=0.019)$ and lipid metabolism disorders $(P=0.049)$.

\section{Multivariable Analysis}

In the GLM model of annual all-cause total costs, 743 patients whose total costs were not 0 without missing categorical variable data were included. In the GLM model of annual CVrelated total costs, 741 patients whose total costs were not 0 without missing categorical variable data were included. In the goodness of fit test of the models, the significance levels calculated by the Deviance test and Pearson Chi-Square test were respectively 1.188 and 1.446 for the all-cause model, 1.277 and 1.415 for the CV-related model, none of which were significant $(P>0.05)$, indicating that the two GLM models fit well.

The multivariable analysis results for annual all-cause and CVrelated total costs of the survivors are shown in Tables 5, 6. For annual all-cause costs, patients whose income per month was more than RMB 2,400 and less than RMB 4,000 $(P=0.003)$, and was more than $\mathrm{RMB} 5,500(P=0.005)$, who sometimes did sports $(P=0.030)$ had significantly higher total costs. Having type 2 diabetes $(P=0.012)$ was also influencing factors that significantly increased the all-cause total costs. Patients who sometimes $(P=0.002)$ and often $(P=0.047)$ smoke, sometimes control high-fat and high-cholesterol diet $(P=0.016)$ had significantly lower total costs. Having PCI $(P=0.000)$ was also influencing factors that significantly decreased the all-cause total costs.

While for annual CV-related costs, patients with basic medical insurance, patients whose income per month was more than RMB 2,400 and less than RMB 4,000 $(P=0.002)$, and was more than RMB 5,500 $(P=0.010)$, who sometimes did sports $(P=0.036)$ had significantly higher total costs. Having type 2 diabetes $(P=0.012)$ was also influencing factors that significantly increased the all-cause total costs. Patients who sometimes $(P=$ $0.003)$ and often $(P=0.005)$ smoke had significantly lower total costs. Having MI history $(P=0.045)$ and PCI $(P=0.012)$ was also influencing factors that significantly decreased the all-cause total costs.

\section{DISCUSSION}

MI is a public health challenge in China and throughout the world. Dyslipidemia is one of the main risk factors for MI, and it also brings a tremendous economic burden on society. However, unlike some European and American countries, no Asian countries, including China, have measured patients' economic burden with MI combined with dyslipidemia. Our investigation is the first study to investigate the costs of patients with MI combined with dyslipidemia in China from the whole society's perspective using the real-world data in China.

In our study, we reported the median annual all-cause and CV-related costs, related studies were very limited. The hospitalization costs per time of patients with MI in Beijing in 2012 were RMB 29,000 (11), which was slightly higher than that (RMB 23,690 in 2017) in our study. Compared with patients' economic burden with MI in other countries (14-16), our study's annual all-cause and CV-related costs were lower. It may be related to differences in sample sizes, medical resource utilization, and MI treatment in different countries. Besides, in our study, $\mathrm{CV}$-related costs accounted for a large proportion of the total allcause costs, indicating that CV-related diseases' economic burden was high.

There were significant differences in both annual all-cause and CV-related total costs in terms of gender, BMI, medical insurance, medical history, and other factors. The average age of all patients in our study was 62.1 years, most of them were between 50 and 70 years and male. The characteristics of gender and age are consistent with other studies that reported baseline information $(11,14,17)$. Costs were also high in those older and retired patients, especially for males. It was showed that MI's economic burden of patients $>60$ years was $\sim 47 \%$ of the total costs in 2012 in Korea (18). Older people may have a greater likelihood of suffering from MI (19), may require a more extended hospital stay to achieve the treatment effect (19), and maybe more likely to have other complications (19), resulting in higher costs.

The all-cause and CV-related total costs were significantly higher among patients with type 2 diabetes. The costs of treatment for the disease, the multiple hospital prescriptions required for chronic disease, and the disease progression of $\mathrm{MI}$ due to type 2 diabetes (20-22) may result in larger numbers and costs for MI hospitalizations. Patients who had been subjected to PCI had lower total costs, and patients with first-episode MI 
TABLE 6 | Multivariate analysis results of cardiovascular-related economic burden on survivors.

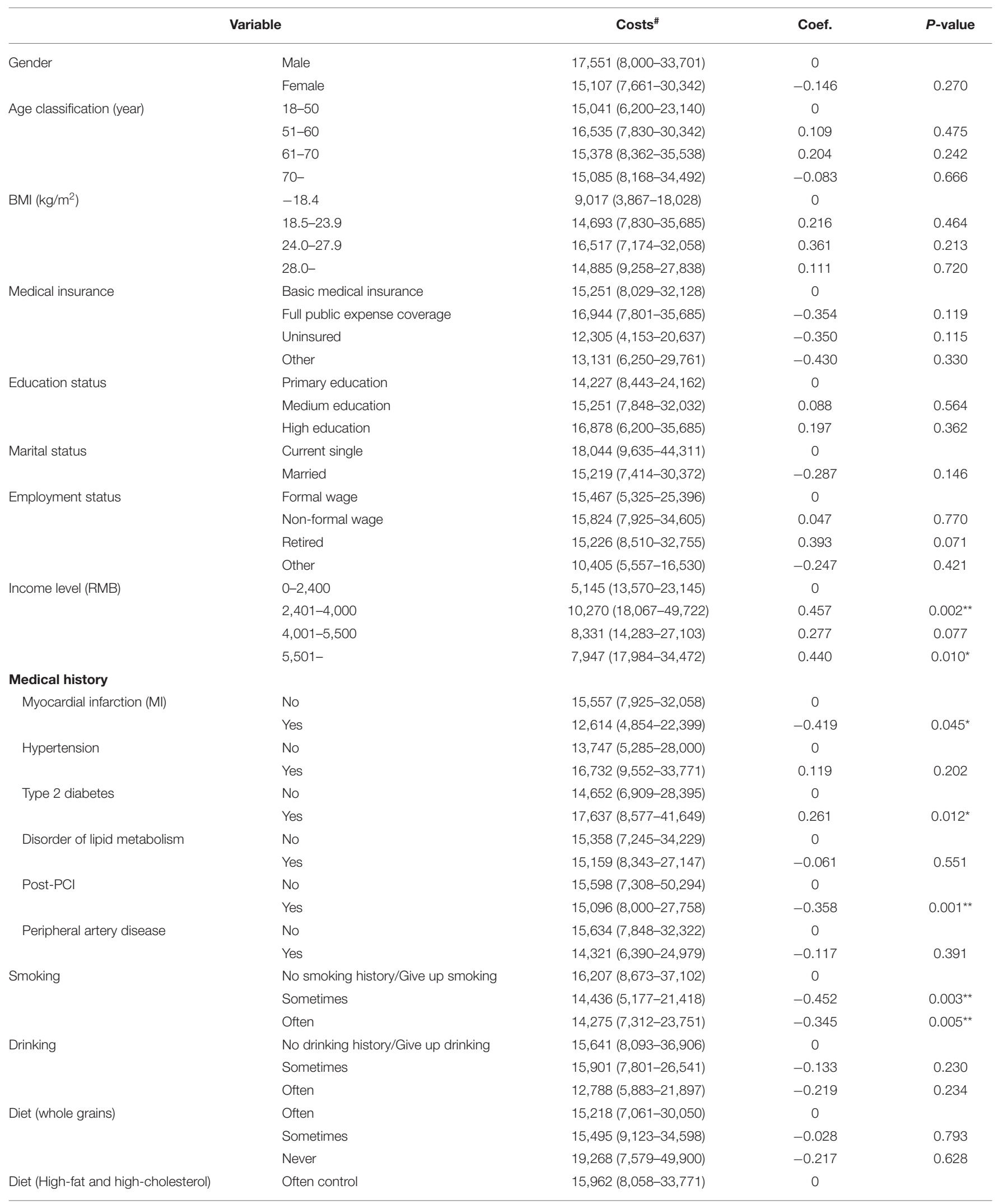


TABLE 6 | Continued

\begin{tabular}{|c|c|c|c|c|}
\hline \multicolumn{2}{|c|}{ Variable } & \multirow{2}{*}{$\begin{array}{c}\text { Costs }^{\#} \\
14,223(6,611-25,787)\end{array}$} & \multirow{2}{*}{$\begin{array}{l}\text { Coef. } \\
-0.211\end{array}$} & \multirow{2}{*}{$\begin{array}{r}\boldsymbol{P} \text {-value } \\
0.066\end{array}$} \\
\hline & Sometimes control & & & \\
\hline & Never control & $16,187(5,978-36,755)$ & -0.024 & 0.916 \\
\hline \multirow[t]{3}{*}{ Sports } & Often & $14,717(6,546-29,253)$ & 0 & \\
\hline & Sometimes & $16,686(9,316-34,605)$ & 0.241 & $0.036^{\star}$ \\
\hline & Never & $16,081(9,524-39,809)$ & 0.164 & 0.220 \\
\hline
\end{tabular}

$\mathrm{PCl}$, percutaneous coronary intervention; BMI, body mass index.

${ }^{*} p<0.05,{ }^{* *} p<0.01$.

\#All the costs were reported as medians and interquartile ranges.

had higher total CV-related costs. It may be because PCI's efficacy $(23,24)$ reduces the number of required hospital stay and visits, patients with a first-episode MI need to be more vigilant about their health.

Smoking and diet did not affect all-cause and CV-related total costs of survivors in an expected way. Some studies $(25,26)$ have shown that never or quitting smoking positively affects the number and risk of hospitalization for MI. The reduction of smoking prevalence decreased the direct medical costs and the mortality of MI that occur before people went to the hospital (27). However, Yegezu et al. (28) observed that survivors with MI were more likely to be smoking patients, and a healthy diet could reduce fat intake, reducing the risk of dyslipidemia. Research showed that the Mediterranean diet reduced cardiovascular death, complications, and hospital admissions of MI (29). In our study, dietary factors had a different impact on the costs than those reported in the above research. The reason may be that patients with high-fat and high-cholesterol intake may also exercise more, resulting in normal blood lipid levels (30, 31). When fat loss from exercise is more than fat intake, the risk of dyslipidemia will be reduced, decreasing costs. More research is needed on the effects of smoking and diet on hospitalization costs and outpatient costs among patients with MI.

The strengths of this study lie in the following. First, from the perspective of target groups, our study is the first to consider the costs of Chinese patients with MI combined with dyslipidemia. Second, from the standpoint of data sources, the study used patients' electronic medical record data as the primary source of real-world data, supplemented by questionnaires. Compared with entirely relying on questionnaires and the patients' subjective recall, the data are more reliable. Third, in terms of costs, compared with similar studies that only consider the direct medical costs or hospitalization costs, the types of costs included in this research are more comprehensive (direct medical costs, direct non-medical costs, and indirect costs). The median annual all-cause and CV-related costs of hospitalization and outpatient of patients are reported, allowing readers to understand the economic burden of this population multi-dimensionally.

Our study also has some limitations. First, data on direct non-medical costs and indirect costs were derived from questionnaires, which can be more subjective than written or electronically recorded data. Second, specific costs regarding medical insurance reimbursement and out-of-pocket were missing; therefore, it was impossible to compare and analyze the out-of-pocket and medical insurance fund expenditures in this study.

\section{CONCLUSIONS}

Chinese patients with MI combined with dyslipidemia have high all-cause and CV-related costs, among which hospitalization and direct medical costs account for a large proportion. Our findings suggest that a healthy lifestyle contributes a lot and optimal precautions and treatments for complications should be emphasized, which can help to reduce the economic burden. It is also anticipated that the descriptive annual costs will act as a significant new resource for the cost-of-illness studies as well as economic evaluations regarding this population.

\section{DATA AVAILABILITY STATEMENT}

The datasets generated for this article are not readily available because sharing of raw data would be contingent on approval from the research ethics office because of the ethics consideration. Requests to access the datasets should be directed tolihongchao@cpu.edu.cn.

\section{ETHICS STATEMENT}

The studies involving human participants were reviewed and approved by Peking University First Hospital; Wuhan Asia Heart Hospital; Guangdong Provincial People's Hospital; Nanjing Gulou Hospital; Sichuan Provincial People's Hospital; Zhongshan Hospital, Fudan University. The patients/participants provided their written informed consent to participate in this study.

\section{AUTHOR CONTRIBUTIONS}

HL, AM, and PC designed this study. Data were collected and managed by YZ, XS, JC, BX, JT, and ZW. PC and MZ performed the statistics using software and drafted the manuscript. HL and AM supervised the data analysis and proposed suggestions for revising the manuscript. All authors critically reviewed the 
manuscript, approved the final version of the manuscript, and agreed to be accountable for the content of the work.

\section{ACKNOWLEDGMENTS}

We acknowledge Amgen Biotech Consultation (Shanghai) Co., Ltd for partly sponsoring this study. We acknowledge Chinese Cardiovascular Association for supporting this study. We

\section{REFERENCES}

1. Commission NHFP. China Health and Family Planning Statistical Yearbook 2017. Beijing: PUMC Press (2017).

2. Hu S, Gao R, Liu L, Zhu M, Wang W. Summary of China cardiovascular disease report 2018. China Circ J. (2019) 34:209-20. doi: 10.3969/j.issn.1000-3614.2019.03.001

3. Grundy SM, Stone NJ, Bailey AL, Beam C, Birtcher KK, Blumenthal RS, et al. 2018 AHA/ACC/AACVPR/AAPA/ABC/ ACPM/ADA/AGS/APhA/ASPC/NLA/PCNA guideline on the management of blood cholesterol: a report of the American College of Cardiology/American Heart Association Task Force on clinical practice guidelines. J Am Coll Cardiol. (2019) 73:e285-350. doi: 10.1016/j.jacc.2018.11.003

4. Lloyd-Jones DM, Morris PB, Ballantyne CM, Birtcher KK, Daly DD Jr., DePalma SM, et al. 2017 Focused update of the 2016 ACC expert consensus decision pathway on the role of non-statin therapies for LDLcholesterol lowering in the management of atherosclerotic cardiovascular disease risk: a report of the American College of Cardiology Task Force on expert consensus decision pathways. J Am Coll Cardiol. (2017) 70:1785822. doi: 10.1016/j.jacc.2017.07.745

5. Jian Z, Qing-qing M, Chun-rong W, Hong LI, Yue Y, Yi Z, et al. Lipid level and distribution in Chinese population over 18 years old. Chinese J Prev Med. (2005) 39:302-5. doi: 10.3760/j:issn:0253-9624.2005. 05.003

6. Tóth PP, Potter D, Ming EE. Prevalence of lipid abnormalities in the United States: the National Health and Nutrition Examination Survey 2003-2006. J Clin Lipidol. (2012) 6:325-30. doi: 10.1016/j.jacl.2012. 05.002

7. Dai J, Qing M, Yang Y. Study on prevalence characteristics of dyslipidemia among adults in nine provinces and cities in China. Chinese $J$ Cardiovasc Dis. (2018) 46:114-8. doi: 10.3760/cma.j.issn.0253-3758.2018. 02.009

8. Prevention NHFPCDC. Report on Nutrition Chronic Diseases of Chinese Residents (2015). Beijing: PMP House (2015).

9. Moran A, Gu D, Zhao D, Coxson P, Wang YC, Chen CS, et al. Future cardiovascular disease in china: Markov model and risk factor scenario projections from the coronary heart disease policy model-China. Circ Cardiovasc Qual Outcomes. (2010) 3:243-52. doi: 10.1161/circoutcomes.109.910711

10. Disease NCC. Report on Cardiovascular Disease of Chinese Patients (2014). Beijing: ECP House (2015).

11. Zhang Q, Zhao D, Xie W, Xie X, Guo M, Wang M, et al. Recent trends in hospitalization for acute myocardial infarction in Beijing: increasing overall burden and a transition from ST-segment elevation to non-ST-segment elevation myocardial infarction in a population-based study. Medicine (Baltimore). (2016) 95:e2677. doi: 10.1097/md.0000000000002677

12. Stevens W, Peneva D, Li JZ, Liu LZ, Liu G, Gao R, et al. Estimating the future burden of cardiovascular disease and the value of lipid and blood pressure control therapies in China. BMC Health Serv Res. (2016) 16:175. doi: 10.1186/s12913-016-1420-8

13. Jo C. Cost-of-illness studies: concepts, scopes, and methods. Clin Mol Hepatol. (2014) 20:327-37. doi: 10.3350/cmh.2014.20.4.327

14. Sugiyama T, Hasegawa K, Kobayashi Y, Takahashi O, Fukui T, Tsugawa Y. Differential time trends of outcomes and costs of care for acute acknowledge all the participants in the data collection and audit process.

\section{SUPPLEMENTARY MATERIAL}

The Supplementary Material for this article can be found online at: https://www.frontiersin.org/articles/10.3389/fpubh. 2021.648172/full\#supplementary-material

myocardial infarction hospitalizations by ST elevation and type of intervention in the United States, 2001-2011. J Am Heart Assoc. (2015) 4:e001445. doi: 10.1161/jaha.114.001445

15. Yang E, Stokes M, Johansson S, Mellström C, Magnuson E, Cohen DJ, et al. Clinical and economic outcomes among elderly myocardial infarction survivors in the United States. Cardiovasc Ther. (2016) 34:4509. doi: 10.1111/1755-5922.12222

16. Bishu KG, Lekoubou A, Kirkland E, Schumann SO, Schreiner A, Heincelman $\mathrm{M}$, et al. Estimating the economic burden of acute myocardial infarction in the US: 12 year national data. Am J Med Sci. (2020) 359:25765. doi: 10.1016/j.amjms.2020.02.004

17. Li J, Li X, Wang Q, Hu S, Wang Y, Masoudi FA, et al. ST-segment elevation myocardial infarction in China from 2001 to 2011 (the China PEACERetrospective Acute Myocardial Infarction Study): a retrospective analysis of hospital data. Lancet. (2015) 385:441-51. doi: 10.1016/s0140-6736(14)60921-1

18. Seo H, Yoon SJ, Yoon J, Kim D, Gong Y, Kim AR, et al. Recent trends in economic burden of acute myocardial infarction in South Korea. PLoS ONE. (2015) 10:e0117446. doi: 10.1371/journal.pone.0117446

19. Chien DK, Huang MY, Huang CH, Shih SC, Chang WH. Do elderly females have a higher risk of acute myocardial infarction? A retrospective analysis of 329 cases at an emergency department. Taiwan J Obstet Gynecol. (2016) 55:563-7. doi: 10.1016/j.tjog.2016.06.015

20. Johansson S, Rosengren A, Young K, Jennings E. Mortality and morbidity trends after the first year in survivors of acute myocardial infarction: a systematic review. BMC Cardiovasc Disord. (2017) 17:53. doi: 10.1186/s12872-017-0482-9

21. Ding Q, Funk M, Spatz ES, Whittemore R, Lin H, Lipska KJ, et al. Association of diabetes mellitus with health status outcomes in young women and men after acute myocardial infarction: results from the VIRGO study. J Am Heart Assoc. (2019) 8:e010988. doi: 10.1161/jaha.118.010988

22. Forcadell MJ, Vila-Córcoles A, de Diego C, Ochoa-Gondar O, Satué E. Incidence and mortality of myocardial infarction among Catalonian older adults with and without underlying risk conditions: the CAPAMIS study. Eur J Prev Cardiol. (2018) 25:1822-30. doi: 10.1177/20474873187 88396

23. Thatcher JL, Gilseth TA, Adlis S. Improved efficiency in acute myocardial infarction care through commitment to emergency department-initiated primary PCI. J Invasive Cardiol. (2003) 15:693-8.

24. Mylotte D, Morice MC, Eltchaninoff H, Garot J, Louvard Y, Lefèvre $\mathrm{T}$, et al. Primary percutaneous coronary intervention in patients with acute myocardial infarction, resuscitated cardiac arrest, and cardiogenic shock: the role of primary multivessel revascularization. JACC Cardiovasc Interv. (2013) 6:115-25. doi: 10.1016/j.jcin.2012. 10.006

25. Xiao H, Qi F, Jia X, Wang Y, Zhang H, Li S, et al. Impact of Qingdao's smokefree legislation on hospitalizations and mortality from acute myocardial infarction and stroke: an interrupted time-series analysis. Addiction. (2020) 115:1561-70. doi: 10.1111/add.14970

26. Cho JH, Kwon HM, Park SE, Jung JH, Han KD, Park YG, et al. Protective effect of smoking cessation on subsequent myocardial infarction and ischemic stroke independent of weight gain: a nationwide cohort study. PLoS ONE. (2020) 15:e0235276. doi: 10.1371/journal.pone.0235276

27. Lightwood JM, Glantz SA. Short-term economic and health benefits of smoking cessation: myocardial infarction and stroke. Circulation. (1997) 96:1089-96. doi: 10.1161/01.cir.96.4.1089 
28. Yegezu Z, Mollon L, Alshayban DM, Bilal J, Bhattacharjee S. Health-related risk behaviors among myocardial infarction survivors in the United States: a propensity score matched study. Res Social Adm Pharm. (2020) 17:30714. doi: 10.1016/j.sapharm.2020.04.018

29. de Lorgeril M, Salen P, Martin JL, Monjaud I, Delaye J, Mamelle N. Mediterranean diet, traditional risk factors, and the rate of cardiovascular complications after myocardial infarction: final report of the Lyon Diet Heart Study. Circulation. (1999) 99:779-85. doi: 10.1161/01.cir.99.6.779

30. Scotto di Palumbo A, Guerra E, Orlandi C, Bazzucchi I, Sacchetti M. Effect of combined resistance and endurance exercise training on regional fat loss. J Sports Med Phys Fitness. (2017) 57:794-801. doi: 10.23736/s0022-4707.16.06358-1

31. Westerterp KR. Exercise, energy balance and body composition. Eur J Clin Nutr. (2018) 72:1246-50. doi: 10.1038/s41430-018-0180-4
Conflict of Interest: Amgen Biotech Consultation (Shanghai) Co., Ltd partly sponsored this study. However, this study is an economic burden investigation, which does not involve any specific products. Therefore, the authors declare that the research was conducted in the absence of any commercial or financial relationships that could be construed as a potential conflict of interest.

Copyright (c) 2021 Chen, Zhang, Zhang, Su, Chen, Xu, Tao, Wang, Ma and Li. This is an open-access article distributed under the terms of the Creative Commons Attribution License (CC BY). The use, distribution or reproduction in other forums is permitted, provided the original author(s) and the copyright owner(s) are credited and that the original publication in this journal is cited, in accordance with accepted academic practice. No use, distribution or reproduction is permitted which does not comply with these terms. 